\title{
1, 9, AND 16 C-BAND HETEROMORPHISMS IN PARENTS OF DOWN'S SYNDROME PATIENTS: DISTRIBUTION AND ETIOLOGICAL SIGNIFICANCE
}

\author{
Patricia H. Lopetégui \\ Department of Biology, Faculty of Science, Ochanomizu \\ University, Otsuka, Bunkyo-ku, Tokyo 112, Japan
}

\begin{abstract}
Summary The C-band areas of chromosomes 1, 9, and 16 were studied in 50 Japanese individuals, parents of Down's syndrome patients. In order to measure these areas, a modular system for semiautomatic quantitative evaluation of images (VIP-11, Olympus) was used. Each area was distributed according to a system of classification proposed by Patil and Lubs (1977). The distribution of the C-band areas for each chromosome appeared to be significantly different from the distribution of these areas in a normal population chosen at random. The role that large constitutive heterochromatin variants may have in the occurrence of nondisjunction is considered.
\end{abstract}

\section{INTRODUCTION}

Constitutive heterochromatin, as revealed by C-band techniques, is present in humans and in most organisms. In humans, constitutive heterochromatin is located at the centromeres of all chromosomes except $Y$, at the secondary constriction (or paracentromeric regions) of chromosomes 1,9, and 16, at the distal part of the long arms of the $Y$ chromosome and at the satellite and short arms of the achrocentric chromosomes (Paris Conference, 1971). Heterochromatin may undergo some morphological variations that are without obvious clinical effect; they involve only these areas, they are present in all cells of an individual, they are stable and they are transmitted from parent to offspring in a Mendelian fashion (Jacobs, 1977). These morphological differences among homologous chromosomes are called heteromorphisms (Paris Conference, 1971. Supplement, 1975). So far, heteromorphisms have been classified mainly according to qualitative methods and their frequency has been studied in normal population as well as in mentally retarded patients and different racial groups (Craig-Holmes et al., 1973; McKenzie and Lubs, 1975; Matsuura et al., 1978; Tharapel and Summitt, 1978). Because of technical reasons, a quantitative analysis of heteromorphic C-bands has been difficult to carry out, and

Received January 17, 1980 
even though several systems have been proposed (Mason et al., 1975; Balícek et al., 1977; Benyush et al., 1977; Patil and Lubs, 1977; Podugolnikova et al., 1979a), a standard quantitative method is not available yet. This fact makes almost impossible the comparison between data obtained by different groups of researchers.

The exact role of heterochromatin has not been determined since the function of heterochromatin, or its basic component-highly repetitive DNA- - is not known yet. A possible association between the presence of one or more particular heteromorphism and clinical anomaly has been studied by several investigators, but so far there is no evidence of a strict relation between the presence of heteromorphism and physical or mental abnormalities (Nielsen et al., 1974a, b; Lubs et al., 1977; Matsuura et al., 1978; Tharapel and Summitt, 1978). Other authors, however, suggest that, although the presence of an extreme heteromorphism does not affect the phenotype of its carrier, it may predispose the carrier to produce children with chromosome abnormalities (Hamerton, 1971; Nielsen et al., 1974c; Halbrecht and Shabtay', 1976).

In this report an attempt has been made to determine through a quantitative method, the distribution of C-band heteromorphisms of chromosomes 1, 9, and 16 in parents of Down's syndrome patients, in Japan. The role that these heteromorphisms may have in the occurrence of Down's syndrome is considered.

\section{MATERIAIS AND METHODS}

In 50 normal and non-consanguineous parents of Down's syndrome patients, the heterochromatic regions of chromosomes $1,9,16$, and 3 were evaluated in cultured peripheral blood lymphocytes, by means of the BSG technique for C-bands according to Sumner (1972).

In every case, 15 to 20 metaphases of good quality were examined directly under microscope to establish the pattern of distribution of the heterochromatin in each individual. Among these, 3 to 5 metaphases at the average level of chromosome condensation were photographed, enlarged, copied, cut out and pasted for measurement.

In order to compare the variations that the heterochromatic regions present, it is necessary to have a standard reference. Patil and Lubs (1977) have proposed using the length of the short arms of chromosome 16 as a standard reference within each cell. The length of the heterochromatic region and that of the short arms of chromosome 16 (or any other segment of euchromatin) depends on size as well as on shape. Considering this fact, measuring the areas of each heterochromatic region and short arms of chromosome 16 was thought to be a more exact means of evaluation of C-band heteromorphisms.

Patil and Lubs (1977) also proposed a system of classification for the relative values of the heterochromatic regions in five levels (Fig. 1).

This classification was used when comparing the data of this report with the

Jpn. J. Human Genet. 


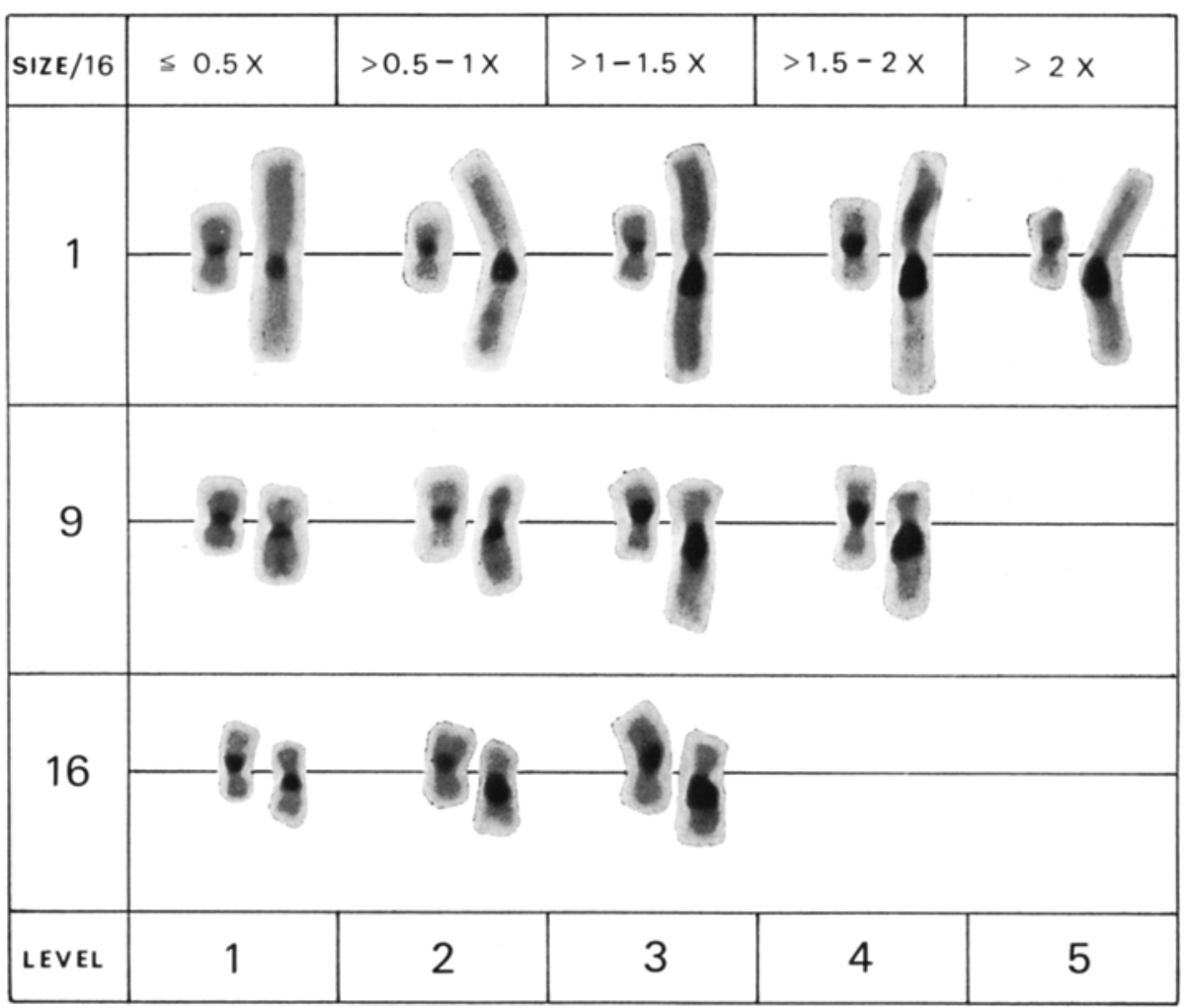

Fig. 1. Classification system for the heterochromatic areas of chromosomes 1, 9, and 16. A representative chromosome of each level was chosen among those observed in this study.

results obtained by Sofuni et al. (1979) in Japanese population. The areas of heterochromatic regions of chromosomes 1, 9, 16, and 3 and short arms of chromosome 16 were measured in a Video Image Processor (Model VIP-11) Olympus.

Considering both interindividual and intraindividual variations of the C-band heteromorphisms, 3 metaphases were chosen at random from each individual. In every case, the chromosomes were measured and considered individually, because it is not possible to establish clearly which chromosome corresponds to those in another metaphase, especially when the variations between homologous are small. As for studying the interindividual variations of the C-band heteromorphisms, 1 metaphase was taken at random from each individual. The heterochromatic region of chromosome 3 was chosen among others because it was considered to be rather stable, thus, it could be used as a standard reference to compare the patterns of distribution that the heterochromatin of clearly heteromorphic chromosomes follows. 


\section{RESULTS AND DISCUSSION}

The distribution of the relative values of the C-band areas for chromosome 3 is shown in Fig. 2. When cells where directly analyzed under microscope, it was considered that the heterochromatic region of chromosome 3 could be used as a standard reference, because of its intermediate size among those in the chromosome complement (McKenzie and Lubs, 1975); besides, chromosome 3 can be easily identified and its heterochromatin appeared to be rather stable. The quantitative method used here, revealed that the majority of chromosomes 3 analyzed present very small variations, as can be seen in Fig. 2. The distribution of these variations is not significantly different from normal distribution $(0.7<\mathrm{p}<0.8)$. However, 3 larger variants, that were not considered in the statistical analysis, were found. Heteromorphisms of the C-band area of chromosome 3 have also been described before (CraigHolmes et al., 1973; McKenzie and Lubs, 1975; Lubs et al., 1977). As all the C-band areas appear to be heteromorphic (Jacobs, 1977), it is almost impossible to use any

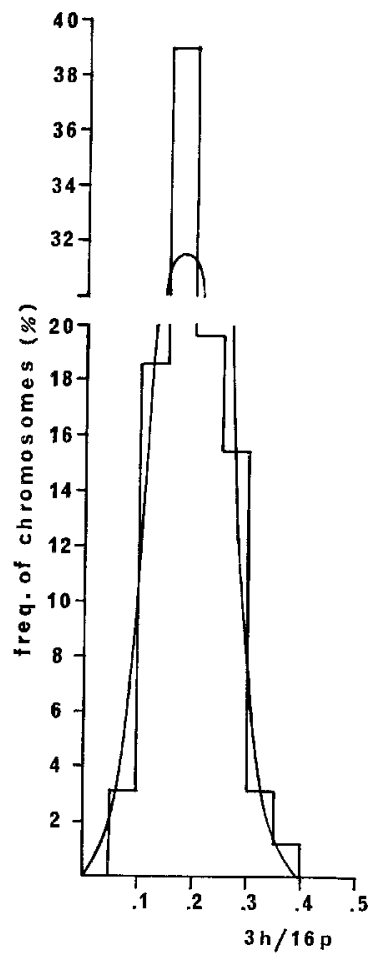

Fig. 2. Distribution of the relative values of the C-band areas for chromosome No. 3. 


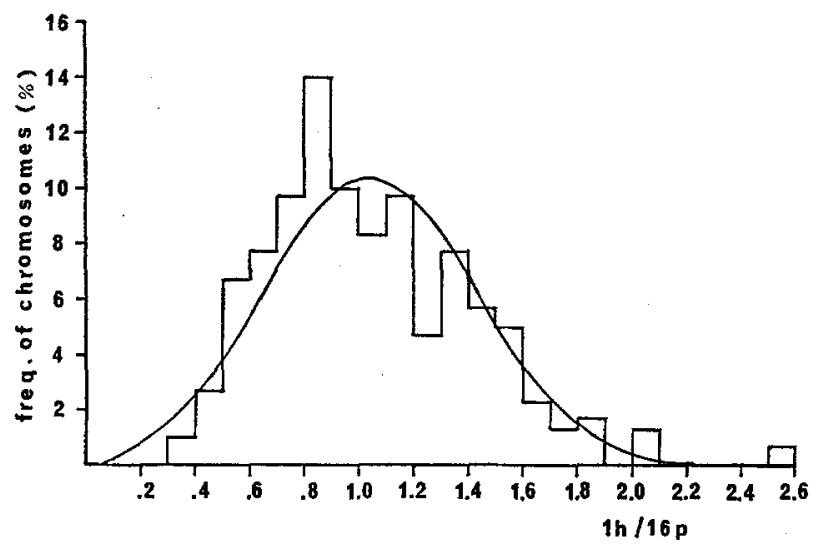

Fig. 3. Distribution of the relative values of the C-band areas for chromosome No. 1.

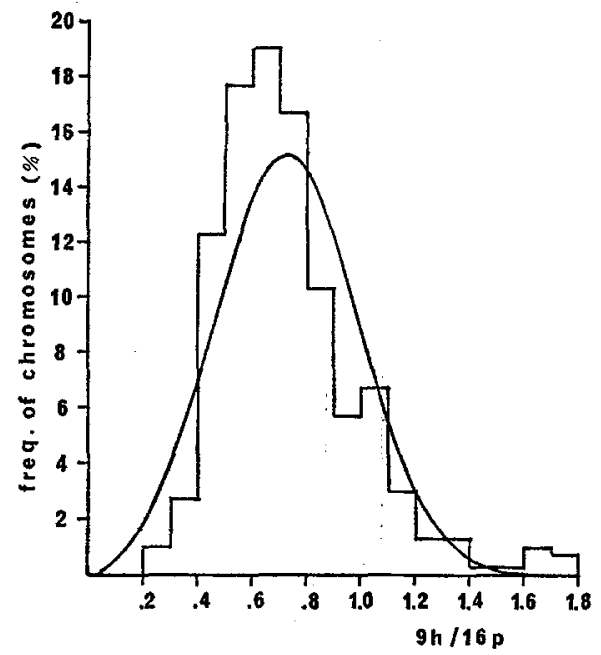

Fig. 4. Distribution of the relative values of the C-band areas for chromosome No. 9.

heterochromatic region as a standard reference for comparing the distribution of heteromorphisms. Nevertheless, it was thought that the distribution that the majority of chromosomes 3 follow, could be used as a standard reference to compare the patterns of distribution of the heterochromatic regions for chromosomes 1,9 , and 16.

Considering interindividual and intraindividual variations, the results obtained for chromosome 1 are shown in Fig. 3. The heterochromatic region of chromosome 1 presents a great variability, that can not be thought as due to technical errors if it is compared with the one obtained for chromosome 3 . In this case, the distribu- 
tion of the relative values of the $\mathrm{C}$-band areas is significantly different from the normal distribution $(\mathrm{p}<0.002)$.

In Fig. 4, the distribution of the relative values of the C-band areas for chromosome 9 is shown. All the variants are included within a wide range, though not as wide as the range of variation of chromosome 1 . This distribution is also significantly different from the normal distribution $(\mathrm{p}<0.0001)$.

Figure 5 shows the distribution of the relative values of the $\mathrm{C}$-band areas for chromosome 16. The range of variation is about the same as the range of variation of chromosome 9 , though a little narrower. The same as in the case of chromosomes 1 and 9, the distribution obtained for the heterochromatic regions of chromosome 16 is significantly different from the normal distribution $(p<0.0001)$.

In all cases the difference between the obtained distribution and the respective normal distribution for each chromosome, is due, mainly, to the presence of larger variants. It may be possible that the heterochromatic regions are not distributed according to normal distribution in the general population either; and, the difference found here is probably due to the origin of these variations in size more than to the presence of extremely large areas of heterochromatin. Podugolnikova et al. (1979b) found that the distribution of heterochromatic regions of chromosomes 1,9 , and 16 in a normal population, followed the pattern of normal distribution. However, since the method of evaluation that they used is different from the one employed in this investigation, it is difficult to compare both data.

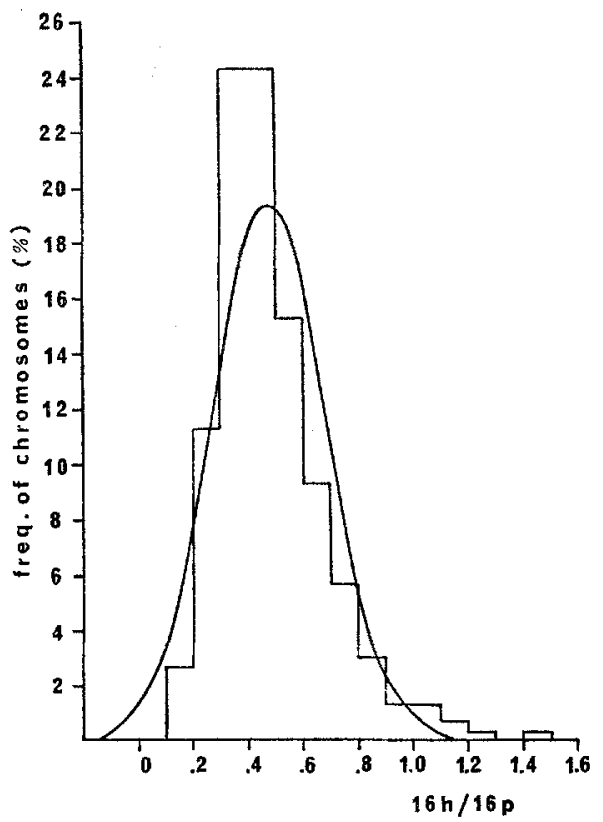

Fig. 5. Distribution of the relative values of the C-band areas for chromosome No. 16.

Jpn. J. Human Genet. 
Table 1. Distribution of the relative values of the C-band areas for chromosomes 1,9 , and 16 according to the classfication proposed by Patil and Lubs (1977).

\begin{tabular}{|c|c|c|c|c|c|c|}
\hline & \multicolumn{2}{|c|}{1} & \multicolumn{2}{|c|}{9} & \multicolumn{2}{|c|}{16} \\
\hline & $\mathrm{a}$ & $\mathrm{b}$ & $a$ & $\mathrm{~b}$ & $a$ & $\mathrm{~b}$ \\
\hline $\begin{array}{c}\text { Level 1 } \\
\leqq 0.5 \times 16 \mathrm{p}\end{array}$ & 1.0 & 4.3 & 11.0 & 8.1 & 62.0 & 76.9 \\
\hline $\begin{array}{l}\text { Level } 2 \\
<0.5-1 \times 16 \mathrm{p}\end{array}$ & 50.0 & 66.7 & 75.0 & 85.5 & 35.0 & 22.6 \\
\hline $\begin{array}{l}\text { Level } 3 \\
>1-1.5 \times 16 \mathrm{p}\end{array}$ & 35.0 & 25.8 & 12.0 & 5.9 & 3.0 & 0.5 \\
\hline $\begin{array}{l}\text { Level } 4 \\
>1.5-2 \times 16 \mathrm{p}\end{array}$ & 10.0 & 2.7 & 2.0 & 0.5 & 0 & 0 \\
\hline \multirow[t]{2}{*}{$\begin{array}{r}\text { Level } 5 \\
>2 \times 16 \mathrm{p}\end{array}$} & 4.0 & 0.5 & 0 & 0 & 0 & 0 \\
\hline & \multicolumn{2}{|c|}{$\mathrm{p} \ll 0.0001$} & \multicolumn{2}{|c|}{$\mathrm{p}<0.005$} & \multicolumn{2}{|c|}{$\mathrm{p}<0.0001$} \\
\hline
\end{tabular}

a, observed values; b, expected values (Sofuni et al., 1979)

Table 1 presents the results of a comparative study between the data obtained from parents of Down's syndrome patients and the data obtained by Sofuni $e t$ al. (1979) from a normal population chosen at random.

When the distribution of the relative values of the C-band areas of chromosomes 1,9 , and 16 obtained in this report, is compared with that obtained in the control group (Sofuni et al., 1979), it appears that each distribution is significantly different from that obtained in the general population. The difference between both data is due to the occurrence of extremely large variants in the distribution of chromosomes 1, 9, and 16 of parents of Down's syndrome patients.

As for the significance of extreme heteromorphisms, reports found in the literature show different opinions. Some authors have not found any strict relation between the presence of one or more particular heteromorphism and chromosomal abnormalities or mental defects (Nielsen et al., 1974a, b; Tharapel and Summitt, 1978; Matsuura et al., 1978); or between the presence of large variants and an increased frequency of abortions in the carriers of heteromorphisms (Nielsen et al., 1974a, b).

On the other hand, prior to the advent of C-bands techniques, Hamerton (1971) said that the frequency of marker chromosomes $(\mathrm{Dp}+, \mathrm{Gp}+, \mathrm{Yq}+)$ in Down's syndrome patients or in other members of the family was too high to be accounted for entirely by chance and it may indicate a predisposition to nondisjunction or structural rearrangement.

Nielsen et al. (1974c) reported a high frequency of $9 \mathrm{qh}+$ among the parents and relatives of children with major chromosome abnormalities, which indicates that the presence of extreme heteromorphisms might give an increased risk of chromosome abnormalities in the progeny. Halbretch and Shabtay (1976) reported the 
presence of extreme $1 \mathrm{qh}+, 9 \mathrm{qh}+, 15 \mathrm{p}+, 21 \mathrm{p}+, 22 \mathrm{p}+$, and $\mathrm{Yq}+$ variants, in a study of seven individuals with different kinds of malformations and their families. Since the variants are present in abnormal individuals as well as in normal members of a family, the authors concluded that probably the presence of one or more heteromorphisms per se does not have a direct effect on the phenotype of the carrier but may increase the risk of nondisjunction and thus, the risk of chromosome abnormalities or malformations in the offspring, including abortion and neonatal death.

The data obtained in this investigation can be taken as another evidence for a possible role of extreme variants of heterochromatin in the occurrence of nondisjunction, by affecting chromosome pairing during meiosis or/and by affecting cellular division in other ways, as stated by Ford and Lester (1978).

Acknowledgments I owe a great debt to Associate Professor Sadao Ishiwa, Department of Biology, Faculty of Science, Ochanomizu University, for his assistance with the statistical analysis and his constant encouragement, and to Professor Akira Tonomura, Department of Cytogenetics, Medical Research Institute, Tokyo Medical and Dental University, under whose guidance this investigation was made possible, for his valuable suggestions and reading of this manuscript. I also wish to thank Dr. Kunikazu Kishi and Miss Fumiko Saitoh, Department of Cytogenetics, Medical Research Institute, Tokyo Medical and Dental University, for their great help during the course of this study.

\section{REFERENCES}

Balíček, P., Zižka, J., and Skalská, H. 1977. Length of human constitutive heterochromatin in relation to chromosomal contraction. Hum. Genet. 38: 189-193.

Benyush, V.A., Luckash, V.G., and Shtannikov, A.V. 1977. Quantitative analysis of C-bands based on optical density profiles in human chromosomes. Hum. Genet. 39: 169-175.

Craig-Holmes, A.P., Moore, F.B., and Shaw, M.W. 1973. Polymorphism of human C-band heterochromatin. I. Frequency of variants. Am. J. Hum. Genet. 25: 181-192.

Ford, J.H., and Lester, P. 1978. Chromosomal variants and nondisjunction. Cytogenet. Cell Genet. 21 : 300-303.

Halbrecht, I., and Shabtay, F. 1976. Human chromosome polymorphism and congenital malformations. Clin. Genet. 10: 113-122.

Hamerton, J.L. 1971. Human Cytogenetics. II. Clinical Genetics. Academic Press, New York, London, p. 236.

Jacobs, P.A. 1977. Human chromosome heteromorphisms. In: Progress in Medical Genetics. New Series, Steinberg, A.G., Bearn, A.G., Motulsky, A.G., Childs, B. eds. Saunders, Philadelphia, pp. 251-274.

Lubs, H.A., Patil, S.A., Kimberling, W.J., Brown, J., Cohen, M., Gerald, P., Hecht, F., Myrianthopoulos, N., and Summitt, R.L. 1977. Q and C polymorphisms in 7 and 8 year old children: racial differences and clinical significance. In: Population cytogenetics. Hook, E.R. and Porter, I.H. eds. Academic Press, New York, pp. 103-159.

Mason, D., Lauder, I., Rutovitz, D., and Spowart, G. 1975. Measurement of C-bands in human chromosomes. Comput. Biol. Med. 5: 179-201.

Matsuura, J., Mayer, M., and Jacobs, P. 1978. A cytogenetic survey of an institution for the mentally retarded. II. C-band chromosome heteromorphisms. Hum. Genet. 45: 33-41.

Jpn. J. Human Genet. 
McKenzie, W.H., and Lubs, H.A. 1975. Human Q and C chromosomal variations: distribution and incidence. Cytogenet. Cell Genet. 14: 97-115.

Nielsen, J., Friedrich, U., and Hreidarsson, Á.B. 1974a. Frequency and genetic effect of 1qht. Humangenetik 21: 193-196.

Nielsen, J., Friedrich, U., Hreidarsson, Á.B., and Zeuthen, E. 1974b. Frequency and segregation of $16 \mathrm{qh}+$. Clin. Genet. 5: 316-321.

Nielsen, J., Friedrich, U., Hreidarsson, Á.B., and Zeuthen, E. 1974c. Frequency of $9 \mathrm{qh}+$ and risk of chromosome aberrations in the progeny of individuals with $9 \mathrm{qh}+$. Humangenetik 21: 211-216.

Paris Conference (1971): Standardization in human cytogenetics, Birth Defects: Original article series, Vol. 8, No. 7, National Foundation-March of Dimes, New York, 1972.

Paris Conference (1971), Supplement (1975): Standardization in human cytogenetics, Birth Defects: Original article series, Vol. 9, No. 9, National Foundation-March of Dimes, New York, 1975.

Patil, S.R., and Lubs, H.A. 1977. Classification of qh regions in human chromosomes 1, 9, and 16 by C-banding. Hum. Genet. 38: 35-38.

Podugolnikova, O.A., Parfenova, I.V., Sushanlo, H.M., and Prokofieva-Belgovskaja, A.A. 1979a. The quantitative analysis of polymorphism on human chromosomes $1,9,16$, and Y.I. Description of individual karyotypes. Hum. Genet. 49: 243-250.

Podugolnikova, O.A., Sushanlo, H.M., Parfenova, I.V., and Prokofieva-Belgovskaja, A.A. 1979b. The quantitative analysis of polymorphism on human chromosomes 1, 9, 16, and Y. II. Comparison of the C-segments in male and female individuals (Group characteristics). Hum. Genet. 49: $251-260$.

Sofuni, T., Naruto, J., and Awa, A. 1979. Quantitative analysis of C-bands based on area measurement. Jpn. J. Human Genet. 24: 194-195.

Sumner, A.T. 1972. A simple technique for demonstrating centromeric heterochromatin. Exp. Cell Res. 75: 304-306.

Tharapel, A.T., and Summitt, R.L. 1978. Minor chromosome variations and selected heteromorphisms in 200 unclassifiable mentally retarded patients and 200 normal controls. Hum. Genet. 41: 121-130. 